\title{
Digitalization of Education: Scientific Consistency vs. Radical Change Under the Impact of COVID-19?
}

\author{
Jana Majerova* \\ University of Zilina, Faculty of Operation and Economics of Transport and Communications, Univerzitna 1, 01026 \\ Zilina, Slovak Republic \\ ${ }^{*}$ Corresponding author. Email: jana.majerova@fpedas.uniza.sk
}

\begin{abstract}
Recently, the digitalization of education has been one of the dynamically developed issues across whole the levels of educational systems. However, the dynamic of the research in this area has accelerated much more than it has been originally expected via extrapolating the time line of research activities. The reason is mainly the pandemic COVID-19 and its impact on the distance learning and ICT technologies incorporation into standard educational processes without previous testing phase. Thus, even the attention paid to the digitalization of education has raised, its practical range has growth unproportionally and current situation has shown that in many aspects real practical needs are not covered by appropriate theoretical approaches. Following this fact, the aim of this paper is to analyse trends in the scientific approaches to the digitalization of education and to state whether there is consistency or radical change in detected trends under the impact of COVID-19. The scientific contribution of the fulfilment of such an aim consists in the identification of convergence eventually divergence between the theory and practice of selected field. Methodologically, bibliometric analysis provided in scope of Web of Science database via VOSviewer platform has been chosen as appropriate one. Based on such an approach, it has been analysed the basic dataset from years 2019-2021 where the consistency resp. radical change in the trends in the digitalization of education under the impact of pandemic COVID19 has been identified. On the case study of this issue, the intensity of interactions between cotemporary theory and practice can be prospectively discussed in wider context of the usefulness of the science.
\end{abstract}

Keywords: Digitalization, Education, Bibliometric analysis, COVID-19.

\section{INTRODUCTION}

Digitalization of education has been one of the hot topics following the trend of social digital transformation [1]. Thus it could be stated, that in the light and shadow of this fact, the pandemic crisis and the phenomenon of "homeeducation" caused by this situation should suffer relatively lower negative aspects in comparison with other parts of human lives and social mechanisms where the digitalization hasn't been originally discusses with such an intensity. However, chronologically were scientific disputes mainly focused on advanced specific issues of digitalization as digital gamification [2]. Other scientific flows have been detected mainly in scope of digital literacy and digital education governance as basic prerequisites of optimal implementation $[3,4]$. Thus, it can be observed the shift from practical application issues like individual tools of digital education and overall digital literacy to the more sophistic ones on the macro level of educational systems. On the other hand, also originally discussed topics have indicated certain gaps in scope of current pandemic situation. Example of such a deficiency is the attention paid to the digital literacy of students. It has been abstracted from the aspect of digital literacy of teaching staff despite the fact that the need of further research of this issue has been already highlighted [5]. According to above mentioned, the situation could evoke the impression that pandemic crisis has radically restructured the scientific interest in scope of digitalizing education. On the other hand, when analysing recent papers included in Web of Science database, the consistency in solved topics can be still observed. Thus, gamification as individual tool of digital education is still present [6,7]. Similarly, digital competences of specific categories of students are still discussed [8]. Governmental support and interventions to the digitalization of education are currently analysed in scope of digital facilities and hierarchical structure of educational institutions [9]. Beside these topics there are 
also many new issues included in Web of Science database which are connected with pandemic situation [10]. It can be stated that the theoretical approaches are fragmented. This fact is prospective barrier of effective digitalization of education. Thus, it should be answered whether the needs of educational practice are followed by the science or the science is living its own life without real interaction with current situation and practical implications of solved problems.

\section{DATA AND METHODOLOGY}

From the methodological point of view, this paper is based on the bibliometric analysis of the data provided via VOSviewer software platform. This freely available platform is standardly used to create citation maps of publications, authors and citation networks. The process of a scientific mapping comprises the following steps: 1) data search; 2) data pre-processing; 3) extraction of the citation map; 4) data standardisation; 5) citation mapping; 6) data analysis, and 7) data visualisation. The essence of the bibliometric analysis lies in the clustering approach. The cluster analysis belongs to methods which deal with a similarity of multi-dimensional objects and a classification of these objects into clusters [11].

Generally, a cluster analysis can be defined as a general logical method formulated as a procedure; it is used to merge objects into groups - clusters, based on their similarity and difference [12]. The cluster analysis can also be used to radically decrease the dimension of a task; the variables under consideration are replaced with a single variable, expressing the affiliation to such a defined cluster [13]. A cluster is a group of objects whose distance (dissimilarity) is less than the distance between objects not belonging to the cluster [14]. A similarity measure of objects $x_{i}$ and $x_{j}$ is noted as $S\left(x_{i}, x_{j}\right)$, or $S_{i j}$ in its short form, and it is true that $\mathrm{S}_{\mathrm{ij}}=\mathrm{S}_{\mathrm{ji}}$. In an ideal case similarity measures take values from an interval, where 0 means the maximum dissimilarity of objects, and 1 means the maximum identity. A dissimilarity measure of objects $\mathrm{x}_{\mathrm{i}}$ and $\mathrm{x}_{\mathrm{j}}$ is noted as $\mathrm{D}\left(\mathrm{x}_{\mathrm{i}}, \mathrm{x}_{\mathrm{j}}\right)$, or $\mathrm{D}_{\mathrm{ij}}$ in its short form, and the following is true: 1) $\mathrm{D}_{\mathrm{ij}} \geq 0$;2) $\mathrm{D}_{\mathrm{ii}}=0$; 3) $D_{i j}=D_{j i}$. The similarity of objects can be measured with different methods which can usually be categorised into the following basic groups: 1) association measures; 2) distance measures (metrics); and 3) correlation measures, where coefficients of association and correlation represent measures of the objects similarity, and the metrics represent measures of the objects dissimilarity [15].

Relevant secondary data has been obtained via analysis of current structure of publications focused on the key words "digital" and "education" in the titles of papers included in the database Web of Science. The observed records can be represented with papers concentrating on the key words "digital" and "education" included in the database Web of Science in years 2019-
2021. Based on the outcomes of this analysis, the consistency resp. radical change in the trends in the digitalization of education under the impact of pandemic COVID-19 can be proven.

\section{RESULTS AND DISCUSSION}

In 2019, 466 papers obtaining key words "digital" and "education" in the titles were included to the Web of Science database. In 2020, it was 451 papers. In 2021, it has been 73 papers in first quarter of the year. On the other hand, also the time delay in indexation (vs. publication of the paper) should be taken into account. Thus, part of the papers, which has been indexed in 2020, were published in 2019. This situation is prospective reason of distortion of own bibliometric research. From regional point of view, in 2019 , the leading country was USA (61 papers), followed by Russia (46 papers) and England (40 papers). In 2020, the leading country was Spain (75 papers), followed by USA (52 papers) and Russia (35 papers). In 2021, Spain remains to be the leading country (12 papers so far), followed by England (8 papers) and Germany, Peoples Republic China and USA (all per 7 papers). From institutional point of view, Nanyang Technological University in Singapore was the most enhanced organization in 2019 (21 papers). In 2020, there were two leading institutions (both per 10 papers) University of Granada, Spain and University of London, United Kingdom. In 2021, the leading institution can not be identified clearly as there are 8 institutions per 2 publications so far. In scope of trends detection, the analysis of the most cited papers would be useful to clarify the results of realized bibliometric analysis. In 2019 , the most cited paper focuses on the phenomenon of the adoption of digitalization of education by teaching staff [16]. This paper has 131 citations so far. However, this paper was published still in January 2019 and thus, it cannot be stated that it has any connection with year trends and pandemic impact analysis. On the other hand, we can clearly state that second and third most cited papers have relevancy to the pandemic situation. Both papers (43 resp. 30 citations) are focused on the usage of virtual reality and simulators in the educational processes of healthcare staff $[17,18]$. In 2020, were two of top three most cited papers directly connected with the pandemic COVID-19 [19,20]. Another paper is focused on global research trends in sustainable digital transformation in higher education [21]. In 2021, authors focus on the research of functionalities of free available learning digital platforms in scope of selected subjects [22,23]. However, the total amount of citations is still not enough reliable to state that this topic is the hot topic of the year in scope of digitalization of education. On the other hand, it can be observed intensive interaction between theory and practical needs created as a result of actual pandemic situation.

Fig. 1 shows graphically the distribution of trends in digital education in year 2019. Trend shown blue 
indicates effectiveness and quality of digital education. Trend shown red covers digital skills, competences and literacy of the subjects - teachers as well as students and trend shown green consists in digital socio-cultural transformation and institutional stratification in scope of digital education. As it is obvious, "green" and "red" trends have strong interaction, while "blue" trend is significantly separated. All detected trends can be considered as general and the further analysis of their development in upcoming pandemic years would be relevant

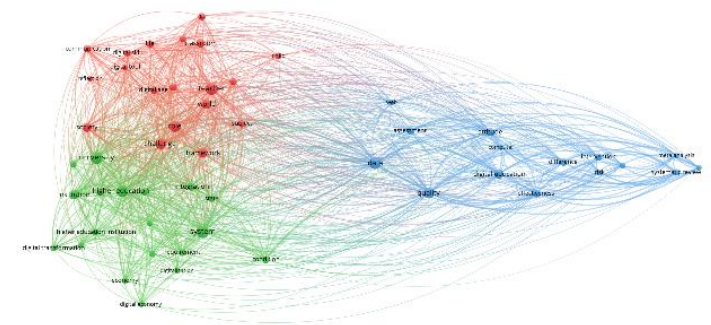

Figure 12019 bibliometric trends in digital education.

Fig. 2 shows graphically the distribution of trends in digital education in year 2020. Similarly, also in this year three trends have been indicated. However, their internal interaction is significant. Trend shown blue indicates ICT institutional level, digital skills, competences and literacy of teaching staff. Trend shown green covers pedagogical challenges and the issue of digital skills, competences and literacy of students. Trend shown red consists in the basic establishment of practical issues in digitalization of educational processes highlighting pandemic impact.

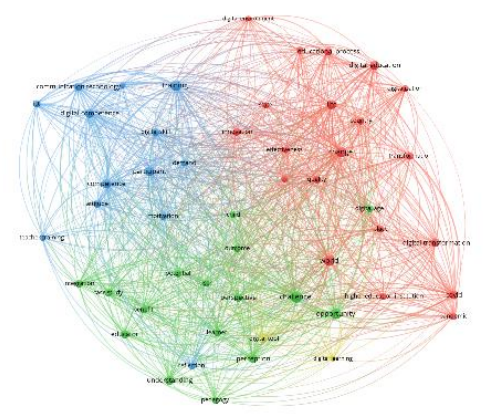

Figure 22020 bibliometric trends in digital education.

Fig. 3 shows graphically the distribution of trends in digital education in year 2021. Also in this year three autonomous trends with strong interactions have been indicated. Trend shown blue covers pedagogical challenges of digitalization in higher education. Trend shown red consists in the effectiveness of selected digital platforms and the transfer of knowledge and best practice in this field. Trend shown green covers the development of digital skills of subjects and their attitudes towards digital pandemic educational challenges.

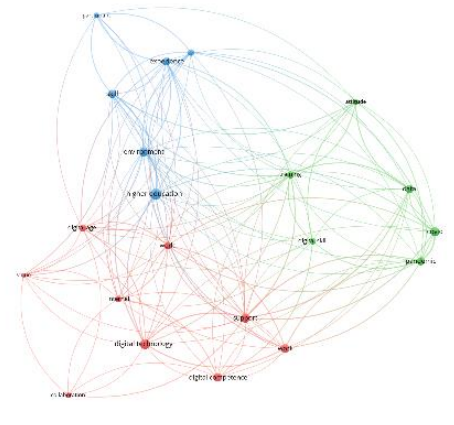

Figure 32021 bibliometric trends in digital education.

No one of the bibliometric analysis outcomes have indicated the convergence between the trends and the topic of the most cited papers. However, it can be stated that pandemic crisis influenced the scientific flows in analysed area. While in 2019, effectiveness and quality of digital education has been indicated as autonomous trend without significant interactions with digital competences and digitalization of education, in upcoming years the situation has significantly changed. The interactions between trends have been detected as intensive and the issue of the quality and effectiveness of digitalization of education has disappeared as it stayed the only one option how to continue with educational processes and the discussion about its quality has become obsolete. However, it can be expected that after pandemic crisis this topic would increase in its theoretical and practical importance.

\section{CONCLUSIONS}

The aim of this paper was to analyse trends in the scientific approaches to the digitalization of education and to state whether there is consistency or radical change in detected trends under the impact of COVID-19. Methodologically, bibliometric analysis provided in scope of Web of Science database via VOSviewer platform was chosen. Based on such an approach, the basic dataset from years 2019-2021 was analysed. The scientific contribution of the fulfilment of such an aim consisteded in the identification of convergence eventually divergence between the theory and practice of the digitalization of education. It was found out that in analyse years these trends were significantly different (mainly when comparing 2019 vs. 2020 eventually 2021). In 2019 these trends were: 1) effectiveness and quality of digital education; 2) digital skills, competences and literacy of the subjects and 3) digital socio-cultural transformation and institutional stratification in scope of digital education. In 2020 these trends could be observed: 1) ICT on institutional level and digital skills of teachers; 2) pedagogical challenges and digital skills of students and 3) practical issues of digitalization in educational processes highlighting pandemic impact. In 2021 the distribution of trends seems to be the following: 1) pedagogical challenges of digitalization in higher education; 2) effectiveness of selected digital platforms 
and the transfer of knowledge and 3) development of digital skills of subjects and their attitudes towards digital pandemic educational challenges. On the case study of this issue, the intensity of interactions between cotemporary theory and practice have been detected as unsatisfactory for the purposes of practical issues of digitalization of education caused by pandemic crisis. Thus, it has been shown significant divergence between scientific approaches and practical issues. This finding can be also prospectively discussed also wider context of the usefulness of the science for the needs of practice and social sustainable development achievement.

\section{ACKNOWLEDGMENTS}

This paper is an output of the project KEGA 043ŽU4/2019: Support and development of digital skills of students in the context of the requirements of the new economy.

\section{REFERENCES}

[1] Kaplan, A. M., \& Haenlein, M. (2016). Higher education and the digital revolution: About MOOCs, SPOCs, social media, and the Cookie Monster. Business Horizons, 59(4), 441-450. https://doi.org/10.1016/j.bushor.2016.03.008

[2] Gros, B. (2007). Digital games in education: The design of games-based learning environments. Journal of Research on Technology in Education, 40(1), 23-38.

[3] Gutierrez Martin, A., \& Tyner, K. (2012). Media education, media literacy and digital competence. Comunicar, 19(38), 31-39. https://doi.org/10.3916/C38-2012-02-03

[4] Williamson, B. (2016). Digital education governance: Data visualization, predictive analytics, and "real-time" policy instruments. Journal of Education Policy, 31(2), 123-141. https://doi.org/10.1080/02680939.2015.1035758

[5] Kreijns, K., Van Acker, F., Vermeulen, M., \& van Buuren, H. (2013). What stimulates teachers to integrate ICT in their pedagogical practices? The use of digital learning materials in education. Computers in Human Behavior, 29(1), 217-225. https://doi.org/10.1016/j.chb.2012.08.008

[6] Obana, T., Takubo, M., Orito, Y., Murata, K., Sai, H., \& Okamoto, T. (n.d.). The online attention game for digital identity education: An exploratory study. Review of Socionetwork Strategies. https://doi.org/10.1007/s12626-021-00077-6

[7] Murillo-Zamorano, L. R., Lopez Sanchez, J. Angel, Godoy-Caballero, A. L., \& Bueno Munoz, C. (2021). Gamification and active learning in higher education: Is it possible to match digital society, academia and students' interests? International Journal of Educational Technology in Higher Education, $18(1)$, 15. https://doi.org/10.1186/s41239-021-00249-y

[8] Smith, R. A. (n.d.). Pandemic and post-pandemic digital pedagogy in hospitality education for Generations Z, Alpha, and Beyond. Journal of Hospitality \& Tourism Research, 10963480211000818. https://doi.org/10.1177/10963480211000818

[9] Owusu-Ansah, C. M., Rodrigues, A. D. S., \& Van der Walt, T. (2021). Going the full distance: Strategic support for digital libraries in distance education at the University of Education, Winneba in Ghana. Journal of Librarianship and Information Science, 53(1), 3-15. https://doi.org/10.1177/0961000618772871

[10] Adelowo, C. M., \& Surujlal, J. (2020). Academic entrepreneurship and traditional academic performance at universities: Evidence from a developing country. Polish Journal of Management Studies, 22(1), 9-25. https://doi.org/10.17512/pjms.2020.22.1.01

[11] Gajanova, L., Nadanyiova, M., \& Lazaroiu, G. (2020). Specifics in brand value sources of customers in the banking industry from the psychographic point of view. Central European Business $\quad$ Review, 9(2), 1-18. https://doi.org/10.18267/j.cebr.232

[12] Vartiak, L. (2016). CSR reporting of companies on a global scale. Procedia - Economics and finance, 39, 176-183. https://doi.org/10.1016/S22125671(16)30276-3

[13] Parobek, J., Palus, H., Kalamarova, M., Loucanova, E., Supin, M., Krizanova, A., \& Stofkova, K. R. (2016). Energy utilization of renewable resources in the European Union-Cluster analysis approach. Bioresources, 11(1), 984-995. https://doi.org/10.15376/biores.11.1.984-995

[14] Nadanyiova, M., \& Gajanova, L. (2020). The impact of corporate social responsibility on brand loyalty in the process of globalization. V T. Kliestik (Ed.), 19th International Scientific Conference Globalization and Its Socio-Economic Consequences 2019-Sustainability in the GlobalKnowledge Economy (Vol, 74, pp. 04017). E D P Sciences. https://doi.org/10.1051/shsconf/20207404017

[15] Jankalova, M., \& Vartiak, L. (2017). Identification of bases for evaluation of the business excellence status in relation to the CSR concept. International 
Journal for Quality Research, 11(2), 315-330. https://doi.org/10.18421/IJQR11.02-05

[16] Scherer, R., Siddiq, F., \& Tondeur, J. (2019). The technology acceptance model (TAM): A metaanalytic structural equation modeling approach to explaining teachers' adoption of digital technology in education. Computers \& Education, 128, 13-35. https://doi.org/10.1016/j.compedu.2018.09.009

[17] Kyaw, B. M., Saxena, N., Posadzki, P., Vseteckova, J., Nikolaou, C. K., George, P. P., Divakar, U., Masiello, I., Kononowicz, A. A., Zary, N., \& Car, L. T. (2019). Virtual reality for health professions education: Systematic review and meta-analysis by the Digital health education collaboration. Journal of Medical Internet Research, 21(1), e12959. https://doi.org/10.2196/12959

[18] Kononowicz, A. A., Woodham, L. A., Edelbring, S., Stathakarou, N., Davies, D., Saxena, N., Car, L. T., Carlstedt-Duke, J., Car, J., \& Zary, N. (2019). Virtual patient simulations in health professions education: systematic review and meta-analysis by the digital health education collaboration. Journal of Medical Internet Research, 21(7), e14676. https://doi.org/10.2196/14676

[19] Iivari, N., Sharma, S., \& Venta-Olkkonen, L. (2020). Digital transformation of everyday lifeHow COVID-19 pandemic transformed the basic education of the young generation and why information management research should care? International Journal of Information Management, 55 , 102183. https://doi.org/10.1016/j.ijinfomgt.2020.102183

[20] Williamson, B., Eynon, R., \& Potter, J. (2020). Pandemic politics, pedagogies and practices: Digital technologies and distance education during the coronavirus emergency. Learning Media and Technology, 45(2), 107-114. https://doi.org/10.1080/17439884.2020.1761641

[21] Abad-Segura, E., Gonzalez-Zamar, M.-D., Aand, J. C. I.-M., \& Ruiperez Garcia, G. (2020). Sustainable management of digital transformation in higher education: Global research trends. Sustainability, 12(5), 2107. https://doi.org/10.3390/su12052107

[22] Svendsen, J. T., \& Svendsen, A. M. (2021). Not for Free! An analysis of two digital tools recommended as learning resources for physical education in upper secondary schools in Denmark. Scandinavian Journal of Educational Research, 65(2), 331-344. https://doi.org/10.1080/00313831.2019.1705896

[23] Gajanova, L., Nadanyiova, M., \& Moravcikova, D. (2019). The use of demographic and psychographic segmentation to creating marketing strategy of brand loyalty. Scientific Annals of Economics and Business, 66(1), 65-84. https://doi.org/10.2478/saeb-2019-0005 